\title{
6 OPEN ACCESS \\ The collaborative communication model for patient handover at the interface between high-acuity and low-acuity care
}

Giulio Toccafondi, ${ }^{1}$ Sara Albolino, ${ }^{1}$ Riccardo Tartaglia, ${ }^{1}$ Stefano Guidi, ${ }^{2}$ Antonio Molisso, ${ }^{3}$ Francesco Venneri, ${ }^{3}$ Adriano Peris, ${ }^{4}$ Filippo Pieralli, ${ }^{4}$ Elisabetta Magnelli, ${ }^{4}$ Marco Librenti, ${ }^{3}$ Marco Morelli, ${ }^{3}$ Paul Barach ${ }^{5}$

${ }^{1}$ Patient Safety and Clinical Risk Management Center, Tuscany GRC, Florence, $\mathrm{FI}$, Italy

${ }^{2}$ Communication Science, University of Siena, Siena, SI, Italy

${ }^{3}$ Department of Vascular Surgery,Florence Health Care Trust ASF, Florence, FI,Italy ${ }^{4}$ Emergency Department, Careggi Teaching HospitalAOUC, Florence, Italy ${ }^{5}$ UMC Utrecht, Netherlands

Correspondence to Dr Giulio Toccafondi, Clinical Risk Management and Patient Safety CentreTuscany Region, Via Taddeo Alderotti 26N, Firenze 50139, Italy; toccafondig@aou-careggi. toscana.it

Accepted 6 September 2012 Published Online First 24 October 2012

\section{ABSTRACT}

Background: Cross-unit handovers transfer responsibility for the patient among healthcare teams in different clinical units, with missed information, potentially placing patients at risk for adverse events. Objectives: We analysed the communications between high-acuity and low-acuity units, their content and social context, and we explored whether common conceptual ground reduced potential threats to patient safety posed by current handover practices.

Methods: We monitored the communication of five content items using handover probes for 22 patient transitions of care between high-acuity 'sender units' and low-acuity 'recipient units'. Data were analysed and discussed in focus groups with healthcare professionals to acquire insights into the characteristics of the common conceptual ground.

Results: High-acuity and low-acuity units agreed about the presence of alert signs in the discharge form in $40 \%$ of the cases. The focus groups identified prehandover practices, particularly for anticipatory guidance that relied extensively on verbal phone interactions that commonly did not involve all members of the healthcare team, particularly nursing. Accessibility of information in the medical records reported by the recipient units was significantly lower than reported by sender units. Common ground to enable interpretation of the complete handover content items existed only among selected members of the healthcare team.

Conclusions: The limited common ground reduced the likelihood of correct interpretation of important handover information, which may contribute to adverse events. Collaborative design and use of a shared set of handover content items may assist in creating common ground to enable clinical teams to communicate effectively to help increase the reliability and safety of cross-unit handovers.

\section{INTRODUCTION}

The lack of effective communication is a contributing cause for several sentinel events that occurred from 2009 to 2011 in the $\mathrm{USA}^{1}$ and for adverse events in the UK. ${ }^{2}$ Many studies demonstrate how poor communication during the exchange of medical information contributes to handover incidents and inefficacy of care processes. ${ }^{3} 4$ The modalities used to deliver medical information are important for patient safety in healthcare systems. ${ }^{5-8}$ The design and management of the Health Information Technologies (HIT) for patient handover, ${ }^{9}$ the organisational procedures ${ }^{10}$ and the patterns of interactions of healthcare practitioners (eg, face-to-face and textual), ${ }^{11}$ may hamper the coordination of care process and the efficacy of patient handovers. One of the problems with systems that rely solely on verbal transmission of information is that only a small part of the original information is retained after a few handover cycles. ${ }^{11}$

Continuity of care $^{12}$ requires tailored design interventions underpinned by human factor principles applied to the interfaces between healthcare professionals and teams. The coordination of care requires seamless interactions at the care interfaces across the system. We defined patient handover as 'the transfer of professional responsibility and accountability for some or all aspects of care for a patient, or group of patients, to another person or professional group, on a temporary or permanent basis'. ${ }^{13}$

Cross-unit handovers occur between different care units within a healthcare system, or among different settings within the larger system. They have been identified as a vulnerable aspect of the care process, ${ }^{14}$ they constitute a human factors design challenge, ${ }^{15}$ and they require a shared mental model and a standardised framework to be effective. ${ }^{16}$ Shared goals and flexible standardisation ${ }^{14} \quad{ }^{17-19}$ are achievable 
through the continuous joint collaboration of healthcare professionals. Tools to facilitate information sharing have been shown to require adaptation to improve practitioner acceptance and use and effectiveness. ${ }^{20} 21$

In cross-unit handovers, the receiving unit accepts responsibility for the patient from the sending unit, and receives information including the patient's history, current status and potential warning signs from the sending unit. While the sending unit has responsibility for shaping the handover to ensure the receiving unit is aware of the needs of the patient and likely contingencies, safe and effective and reliable interunit handovers depend on the actions of both the sender and the receiving unit.

The activity patterns of the sender unit may influence the time available for the handover, and how it is performed. For instance, medical documentation in high-acuity units embeds the point of view of the sender unit, which may or may not be relevant to the low-acuity recipient unit. This may create bias and misunderstanding that may reduce patient handover efficacy and safety. Much of the research on transitions of care has focused on handovers within the same care unit, ${ }^{22}{ }^{23}$ although there is a small but growing body of work on systems to support cross-unit handovers. ${ }^{24-26}$ The conceptual framework, known as the cooperative communication model, suggests that human communication is underpinned by the ability to create a common conceptual ground. ${ }^{27}$ Common ground refers to the pertinent mutual knowledge, beliefs and assumptions that support interdependent action, and an ongoing process of tailoring, updating and repairing mutual understanding. ${ }^{28}$ It is constructed by three skills: the ability to share, inform and request; the ability to jointly share attention and intentions with others ${ }^{29}$; and the ability to construct common cultural knowledge. While the motivation to share and the ability to intentionally join with the action plans of others are biologically coded in the behaviour of human beings, the ability to construct common ground is culturally determined and, therefore, is modifiable. ${ }^{30}$ Abbreviated forms of communications are used to convey articulated messages if a common ground is well developed among participants. Equally tantalising is that there seems to be an inverse relationship between common ground and the need for explicit communication, with more common ground requiring less explicit communication. At the same time, this highly effective 'implicit coordination' may create potential threats to patient safety. ${ }^{31}$

Verbal hints and abbreviations may not be transparent to members of different teams or members of the same team who do not share the common ground. Finally, handover practices used in internal end-of-shift changes may not be appropriate for wholesale adoption in transitions of care among settings, and may require adaptation.

In our study, we considered the communication modalities in patient handovers from high-acuity to low-acuity patient care units. We considered the common conceptual ground underpinning communication of medical information at the transition of care, with the aim of identifying the contributing factors to adverse events that may result from poorly designed handover practices.

\section{METHODS}

The role of context in the implementation of patient safety practice has been widely acknowledged, ${ }^{32}$ and may 'trump' official organisational procedures and coded practices, which constitute a limited part of patient handovers. ${ }^{33}$ To understand how handovers are organised, we included both the high-acuity sender units and the low-acuity recipient units in our analysis.

\section{Study design}

The objective of the study was to assess the continuity of information transfer and the presence of a common ground supporting the communication during cross-unit patient handover. The data acquired were analysed and discussed statistically, with the practitioners taking part in the study in focus-group interviews.

\section{Setting}

The study was coordinated by the Tuscany Region Patient Safety and Clinical Risk Management Center (GRC) as an initial study to lay the groundwork for further interventions. The study was conducted between August 2011 and October 2011 in a teaching hospital (Azienda Ospedaliero Universitaria Careggi) and a territorial hospital (Nuovo San Giovanni di Dio) in the Florence urban area. The ethics committee of the two healthcare units involved endorsed the study.

\section{Phase 1: team building and definition of the group objectives}

Members of the risk management centre invited several practitioners in the handover workgroup. The group developed a study to focus on patient handovers during transitions of care from the intensive care units (ICUs) to low-acuity care units. The study traced the cross-unit handovers of 15 patients in two local healthcare setting with the objective of evaluating the level of agreement between the two units on handover processes, as well as the communication modalities used. 
Phase 2: design and evaluation of the handover probe

To meet the study objectives, the healthcare professionals were asked to collect data on the cross-unit handovers through filling in handover probes ${ }^{34}$ and focus-group interviews (figure 1). We adapted the cultural probes $^{35}$ to the healthcare context in order to elicit the perception of healthcare practitioners regarding handover practices. The first step in designing the handover probe and identifying the handover content items to be evaluated involved semistructured interviews and observations of handovers. These were complemented, when possible, with the collection of formal and informal artefacts (eg, personal notes, informal checklist) that supported the handover processes. ${ }^{36}$ The clinical risk management network collaboratively designed the handover probe using a user-centred approach engaging clinicians throughout the process. ${ }^{37} 38$

The probe was internally evaluated and delivered to healthcare professionals for in-situ observation. The objective of the handover probe was twofold: to monitor the communication transfer among units for an agreed set of five handover content items, ${ }^{39}$ and to compare participants' perceptions on the presence and use of this content. The content related to the present condition as well as to the anticipatory guidance, that is, the explicit concerns of the discharging practitioners about the patient's possible clinical course based on their recent experience with the patient and their responses to previous interventions ${ }^{26}$ (box 1).

The content items were included in the handover probe, and each of the items was verified for their clinical relevance by the practitioners. The probes were structured in two identical parts; one to be completed by the sender, and the other by the receiver, with both completing them independently. The probes were transmitted by means of the discharge form (DF). Observers in each unit filled in the handover probes collecting the perceptions of the practitioner while performing the

\section{HANDOVER PROBES}

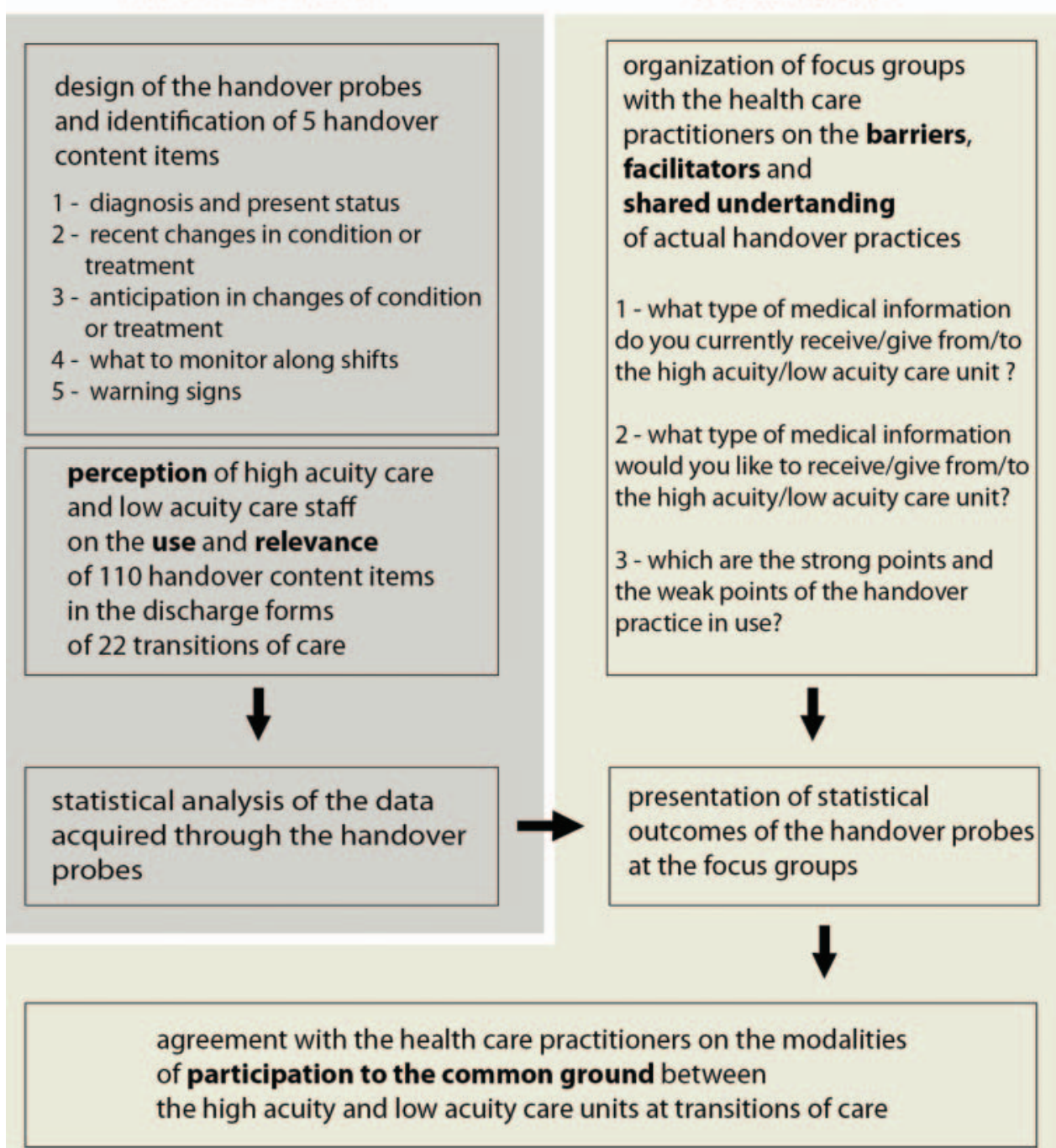

Figure 1 Flowchart showing the modalities of data collection, the phases of the study and the output. 


\section{Box 1 Content of handover probes}

1. Diagnosis and present state of the patient

2. Recent changes in the conditions or treatment

3. Anticipation in changes of conditions or treatment

4. What to monitor along shifts (physicians and nurses)

5. Warning signs

handover. The communication modalities considered were: face-to-face, paper, software/intranet or telephone. The aim was to analyse the handover process in order to understand if the additional information could be easily retrieved in the medical records and matched the DF, how handover was actually (naturalistically) performed, and to identify critical aspects concerning information transfer.

\section{Phase 3: focus-group organisation}

The healthcare practitioners from the healthcare units who filled in the probes participated in two focus-group interviews. ${ }^{38}$ These were used to triangulate the data from the handover probes and to discuss the critical points that emerged from the analysis of this data. ${ }^{40} 41$

\section{Data collection}

In each healthcare unit, one hospital physician and one nurse were in charge of observing patient handovers using the probe. The observer and the observed were equally involved in analysing the handover process, and were asked to observe what types of tools and work patterns were mediating the activity. The handover probe was aimed at observing how and when the five content items were transferred between the two units of care.

\section{Statistical analysis}

The outcomes of the handover probes were analysed by describing how the information was transferred. The workgroup collected complete data regarding the transition of 22 patients. 11 patients were transferred from the emergency ICU to the high-dependency unit in the referral teaching hospital; and 11 patients were transferred from the general ICU to the general surgery ward of the regional hospital. In eight cases, the handover probes were discarded because only one unit provided data. For the sender units, the choice of the patients was discretional (the Glasgow Coma Scale score at admission was recorded). The healthcare practitioner types involved in the study included intensivists, nurses and general physicians. All providers were actively involved as stakeholders in the pilot study.

We counted the number of content items reported as (a) present in the DF and (b) relevance to each unit, for each patient/handover monitored, to assess the quantity of information present in the DF and its perceived relevance to both participants in the handover process. We then compared these measures with correlated sample $t$ tests, matching the senders' and recipients' judgments by patient (ie, handover). We also computed the measures of the agreement between the sender and recipient in regard to the relevance and presence in the DF of each content item listed in the probe.

We used McNemar's test of correlated proportions to check whether the response probabilities to the corresponding questions in the probe for the sender were the same or different than those for the recipient (hypothesis of marginal homogeneity). Finally, we compared the correlated sample $\mathrm{t}$ tests, sender and recipient ratings (matched by patient) of the accessibility of the different content items, as well as the average accessibility of the information (across content type). All the statistical analyses were conducted using the statistical software SPSS V.11 for Mac.

\section{Focus group}

We organised two focus-group sessions in each setting. Participants included four physicians (two from highacuity care units and two from low-acuity care units), and five nurses (two from ICU and three from High Dependency Unit (HDU)) in one setting, and two physicians (one from high-acuity care and one from surgery ward), and three nurses (one from ICU and two from the surgery ward) in the other.

The focus group discussed the perceived critical elements related to handovers between high-acuity and low-acuity units, and acquired the different points of view of the healthcare practitioners. They also assessed the degree of satisfaction of the interacting care units regarding the current handover practices, identified possible gaps between the perception of actual practices and potential improvements. Participants were informed about the objectives of the sessions, and were asked these questions:

a) What type of medical information do you currently receive from the high-acuity care unit?

b) What type of medical information do you currently give to the low-acuity care unit?

c) What type of information would you like to receive from the high-acuity unit?

d) What type of information would you like to give to the low-acuity unit?

e) Which are the strong points and weak points of the handover practice as it is currently organised?

The answers were written by the participants on post-it notes and coded by the researchers in four different clusters: what is shared among the two units, what is not shared, what facilities good handovers, and what is 
perceived as a barrier. The focus-group interviews also elicited important aspects regarding the modality used to transfer the handover content items. They were used to contextualise the outcomes of the handover probes, and we focused on the critical elements that emerged from statistical analysis.

\section{RESULTS}

Information transfer: quantity, accessibility and relevance The total number of content items reported as (a) present in the DF, and (b) relevant by the different units (averaged across handovers) are reported in figure 2. The sender unit reported the presence of a significantly higher amount of information in the DF than the recipient unit $(\mathrm{t}(19)=4.075 ; \mathrm{p}<0.01)$, which primarily related to the amount of information about the anticipatory guidance (predictable changes, warning signs and what to monitor) present in the DF $(\mathrm{t}(19)=4.395 ; \mathrm{p}<0.0001)$. The judgments of the sender unit about the overall relevance of the information in the DF were also significantly higher than that of the recipient unit $(\mathrm{t}(19)$ $=2.138 ; \mathrm{p}<0.05)$. Interestingly, the judgments about the amount of information in the DF, and the relevance of this information, was different for professionals in the
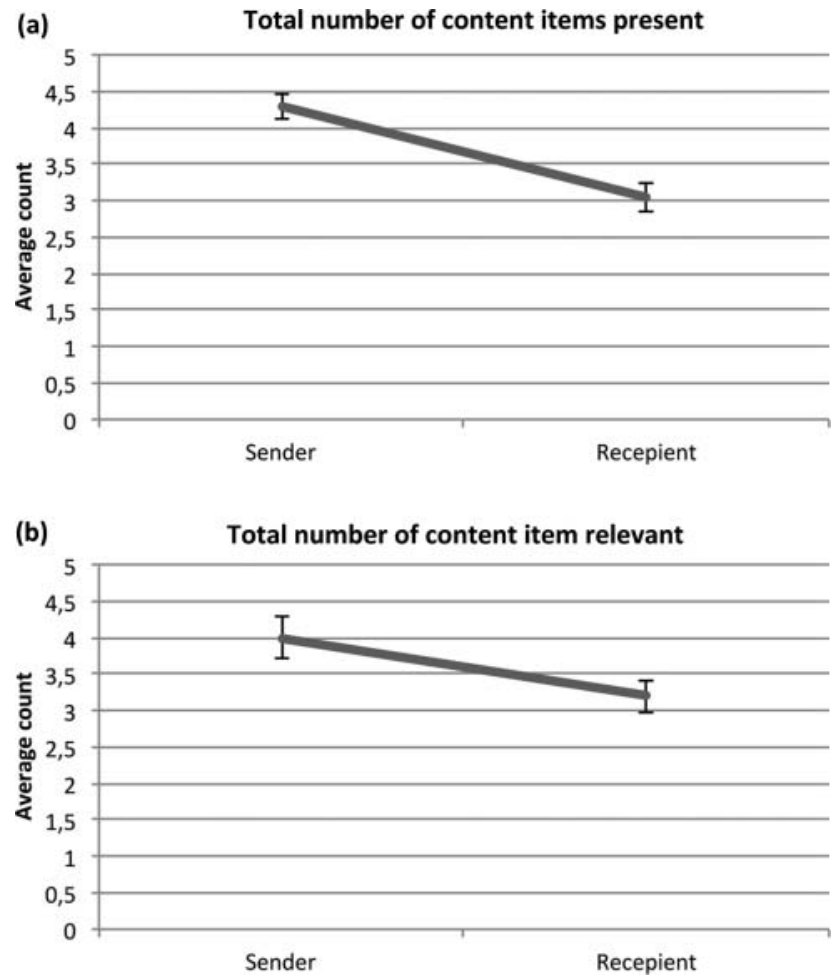

Figure 2 Total numbers of content items reported by the different units as $(A)$ present in DF and $(B)$ relevant. Data are averaged across the different handover monitored $(n=22)$. Error bars are standard errors.

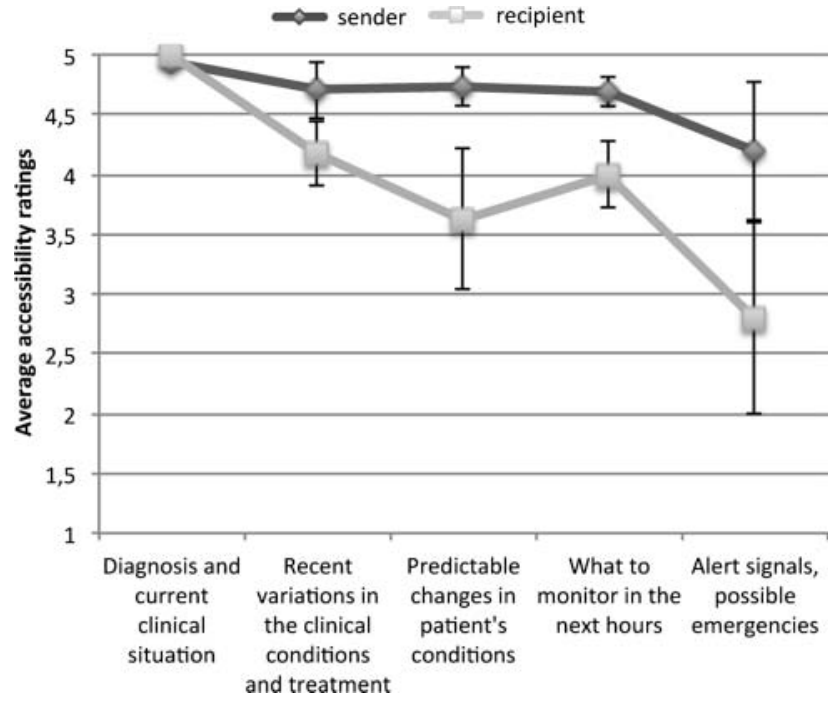

Figure 3 Average accessibility ratings for the different content items made by the different units. Data are averaged across different handover. Error bars are standard errors.

different units. We expected them to be correlated, due to the fact that they concerned the same patients.

The average accessibility of the additional information in the medical records (across different items) reported by recipient units was significantly lower than that reported by sender units $(\mathrm{t}(19)=-3.605 ; \mathrm{p}<0.01)$, with differences in the rating for accessibility of the item related to elements that should be monitored being the only difference that was statistically significant $(t(15)=$ $-2.711 ; \mathrm{p}<0.05)$. In figure 3 , we report on the averaged accessibility ratings for the different content items made by sender and receiving units.

\section{Information transfer: agreement between sender and recipient units}

The overall proportion of responses by senders and recipients about the presence in the DF, and the relevance of the different content items in the probe, are reported in table 1 . The analysis revealed that there was little agreement between healthcare professionals from high-acuity and those from low-acuity units, suggesting different mental models. Perfect agreement was found for the item relative to the diagnosis and the patient's present situation, which were consistently reported as present in the DF, relevant and highly accessible by both units. Good agreement was found about the relevance and presence in the DF of the items relative to what to monitor, and to recent changes in the patient's condition. For the other two items-anticipation in changes of conditions or treatment, and warning signs-the agreement was much smaller.

The two units agreed about the presence in the DF of information about predictable changes in the patient's 
Table 1 Percentage of the times the different content items were reported as (a) present in the discharge form (DF), and (b) relevant, by the sender and the recipient unit in the monitored handover processes $(n=22)$

\begin{tabular}{|c|c|c|c|c|c|c|}
\hline \multirow[b]{2}{*}{ Content item } & \multicolumn{3}{|l|}{ Present in DF } & \multicolumn{3}{|l|}{ Relevant } \\
\hline & Senders (\%) & Recipients (\%) & p Value* & Senders (\%) & Recipients (\%) & p Value* \\
\hline $\begin{array}{l}\text { Diagnosis and present state of the } \\
\text { patient }\end{array}$ & 100 & 100 & - & 96 & 91 & 1 \\
\hline $\begin{array}{l}\text { Recent changes in the conditions or } \\
\text { treatment }\end{array}$ & 96 & 76 & 0.375 & 96 & 67 & 0.063 \\
\hline $\begin{array}{l}\text { Anticipation of changes in condition } \\
\text { or treatment }\end{array}$ & 91 & 38 & 0.006 & 86 & 55 & 0.109 \\
\hline $\begin{array}{l}\text { What to monitor along shifts } \\
\text { (physicians/nurse) }\end{array}$ & 96 & 71 & 0.125 & 82 & 76 & 1 \\
\hline Warning signs & 50 & 10 & 0.02 & 67 & 33 & 0.344 \\
\hline
\end{tabular}

condition only $40 \%$ of the times (95\% CI 0.19 to 0.62 ). The sender units reported that in $91 \%$ of the times, the presence of this content item was in the DF, while the recipient units stated that in $62 \%$ of the times, this information was absent. Not surprisingly, the McNemar's test of correlated proportions rejected the hypothesis of marginal homogeneity between the unit's judgments about the presence of this item in the DF $(\mathrm{p}<0.01)$. This suggests that the probability of reporting the presence of this item in the DF was higher for senders than for recipients. The agreement between the units was slightly higher on the relevance of this content item, but still quite low and not different from chance $(47 \%$ agreement; $95 \%$ CI 0.25 to 0.70 ); the sender units, in fact, considered this item as relevant $86 \%$ of the times, while for the recipients, this was only $55 \%$, although in this case, the McNemar's test for marginal homogeneity was not significant.

The interunit agreement on the presence (in the DF) of information regarding warning signs was also quite low (proportion of agreement: $0.5 ; 95 \%$ CI 0.28 to 0.72 ). According to the sender units, this kind of information was present in $50 \%$ of the cases, while for the recipients it was almost always absent ( $91 \%$ of the times). Once again, a test of correlated proportion rejected the hypothesis of marginal homogeneity $(p<0.05)$ between the judgments of the two units, and the two units agreed only in $20 \%$ of the cases (95\% CI 0.04 to 0.52 ). The sender units considered it relevant $68 \%$ of the times, while the recipient only $33 \%$, but the hypothesis of marginal homogeneity could not be rejected.

\section{Shared understanding and common conceptual ground}

The focus-group data suggest that healthcare professionals are aware of their degree of interdependence, as they raised similar issues and concerns regarding the transitions of care from high-acuity to low-acuity settings. Shared understanding about the patient handover process was generally high in both settings in the pilot. In particular, representatives from both units converged on similar issues regarding the type of information shared and on the type of barriers and facilitators (figures 4 and 5), yet they expressed different views on the added information needed to enhance patient handovers (figure 4).

During the focus groups, the discussion revealed that several face-to-face and verbal contacts occur between the medical staff of the high-acuity and the low-acuity care units before the actual transitions occur, and that future care actions and anticipatory guidance are provided by the sending unit personnel during these conversations, but are not always explicitly mentioned in the DF or the patient's record (figure 6).

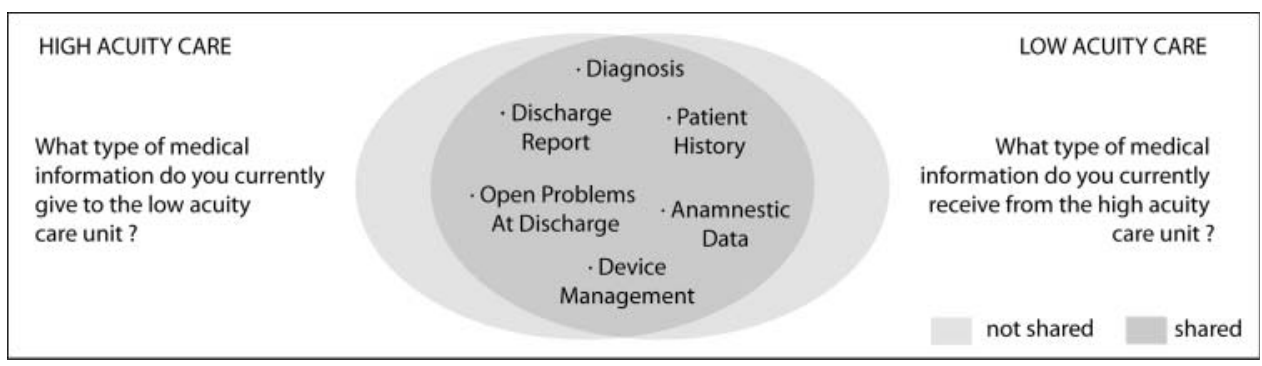

Figure 4 Shared understanding regarding the type of information currently transferred at patient transitions of care. 


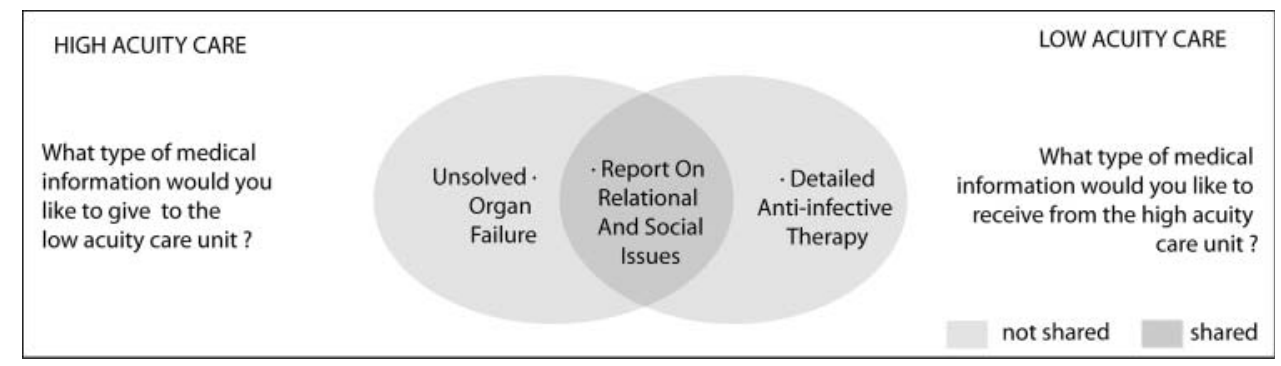

Figure 5 Shared understanding regarding further type of information to be transferred at patient transitions of care.

\section{DISCUSSION}

Our study found discontinuity in information and lack of a common conceptual ground in handovers from high-acuity to low-acuity units that appear to undermine high-quality care. Professionals in high-acuity units held that information regarding anticipatory guidance is not explicitly mentioned in the DF because it is deducible from the 'diagnosis and present patient state' content items, yet this concept was not shared by representatives from the low-acuity units. The focus-group sessions demonstrated that only the members of the medical staff are involved in the prehandover conversation that creates common conceptual ground related to the interpretation of warning signs, and offers anticipatory guidance to the receiving patient unit. Consequently, these dimensions of the handover are not part of the common ground of the nursing staff. Because the physicians' exchange about warning signs and guidance is not formally recorded, and as such, is vulnerable to distortion in subsequent sharing ${ }^{11}$; and, as this exchange also does not involve the nursing staffs of both unit, this may carry inherent risks to patient safety. Finally, the reliance on the prehandover exchange between members of the medical staff causes the recorded information that is occasionally used to make sense of a patient's condition to omit critical information, making it suboptimal for this purpose, as well as a meaningful reconstruction of what actually occurred between the sending and receiving clinicians. Particularly, warning signs and concerns regarding patients' future state, often were not explicitly reported in the DF or in the patient's record.

Handover probes are an experimental method that complement the qualitative analysis and can elicit information on the type and modalities used in communication at patient transitions. Cultural probes are particularly useful when you need to elicit information regarding a process or event taking place intermittently or over a long period. Although our study is based on a limited set of cases, the saturation point regarding the type of handover content items transmitted was reached early in the study. In both settings, the handover probes captured similar patterns of handovers extensively based on prehandover communication that relies on verbal, face-to-face interaction. Content items relating to anticipatory guidance implicitly assigned to the domain 'diagnosis and present state of the patient', or were taken for granted because they were included in the common conceptual ground shared by the members of the medical staff.

The threats to the welfare of patients in the settings observed resulted from two attributes of these handovers. The first threat is contextual and emerges from a well developed common conceptual ground accounting for an implicit anticipatory guidance among the medical staff, in which nursing is only marginally involved. The second threat is technical, and relates to the use of verbal and face-to-face communication without data repositories or redundant systems to ensure information is consistently and reliably transmitted and available to

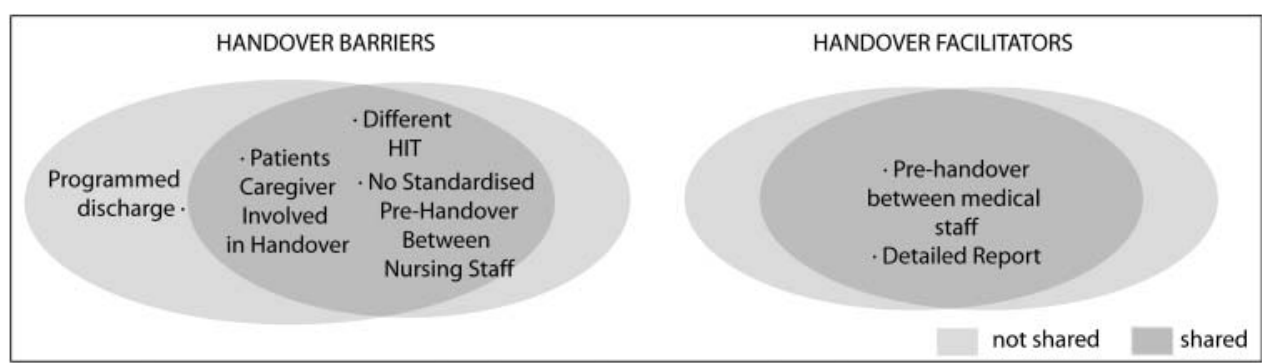

Figure 6 Shared understanding regarding the type of barrier and facilitators for patient transitions of care from high-acuity to low-acuity. 
third parties with a need to know. Observations of the handovers suggest that they are unidirectional, with the sender's perspective as the primary driver of the communication, rather than being a coconstructed process ${ }^{42}$ in its relational exchange of information.

The healthcare providers were directly and eagerly involved in the analysis of their patient handovers which was an important outcome of the study. The observers of the handover processes were trained and supervised by the clinical risk management crew in the use of the handover probes. The direct involvement and engagement of the clinical staff allowed the rare elicitation of perceptions, rarely aired or captured by researchers, on the processes of the clinical staff. Moreover, it included in the pilot phase the same practitioners in charge of the implementation of improvements regarding the handover processes.

The limitations of the study are connected to the fact that this was a pilot analysis and the sample size was small, and that it involved two institutions, limiting the ability to generalise from the findings to other institutions and healthcare settings. To increase the effectiveness and safety of interunit handovers, additional research is needed to develop and test interventions that increase common ground in communication between different care units, and that involve all members of the healthcare team, along with data repositories to augment verbal sharing, and increase the reliability and robustness of the data used to manage patients. The fact that the common ground underpinning current handover practices is unstructured may reduce efficacy and safety. Common ground for healthcare professionals involved in interunit handovers needs to be designed to support mindfulness. ${ }^{43}{ }^{44}$ Mindfulness, which adds resilience in team communication and coordination does not appear to emerge organically from the current routine for communicating medical information. The activations of a cross-unit work group aiming at specific objectives, such as the definition of a check list or a minimum set of handover content items is a viable intervention strategy in the transactions from high acuity to low acuity is an initial step in this process. Future research also should study the influences of internal shift changes on cross-unit handovers. Moreover, the area of accessibility of relevant handover data in patient records needs further consideration, with all members of the healthcare team involved in the design of IT and medical records solutions. ${ }^{45}$

\section{CONCLUSIONS}

This study takes into consideration a theoretically sound communication model for orienting the analysis and the subsequent possible interventions around common ground in communications around cross-unit handovers. The attention to common ground across the different teams involved in patient care will contribute to improved information transfer, and likely will also facilitate a more comprehensive analysis of handover practice. Common ground iteratively constructed while participating in a shared endeavour will render handovers more safe, resilient and effective. Creating this common ground may occur through joint training of sending and receiving units, or joint efforts to critique and improve handover processes. Focusing solely on the information explicitly transferred or recorded in patient care documentation, may result in omission of key information related to warning signs and anticipatory guides.

Finally, our study suggests that medical and nursing staff share the same concerns regarding the handover process, but participate differently in the formulation of conceptual common ground. This requires further study to better understand how to attune these different backgrounds and approaches towards ensuring the quality and safety of patient care during cross-unit transitions.

Acknowledgements We thank all the healthcare providers, patients and clinical risk management staff who participated in this study.

Contributors All authors had full access to all the data in the study, and can take responsibility for the integrity of the data and the accuracy of the data analysis. Study design: GT, SA, RT, SG, AM, FV and AP. Acquisition of data: GT, SA, AM, FV, FP, EM, AP, ML and MM. Analysis and interpretation of data: GT, SA, RT, SG, AM, PB, FV, AP, ML and MM. Drafting of the manuscript: GT, $S G, P B, S A, R T$ and $A M$. Critical revision of the manuscript for important intellectual content: GT, SA, RT, SG, PB, AM and AP. Study supervision: RT, FV and $P B$.

Funding This study was supported by a grant from the European Union, the Framework Programme of the European Commission (FP7-HEALTH-F2-2008-223409). The study sponsor had no role in the study design, collection, analysis and interpretation of the data, or in the writing of the article and decision to submit the article for publication.

\section{Competing interests None.}

Ethics approval Tuscany Region-Ethics Committee ASF, Ethics Committee AOUC.

Provenance and peer review Not commissioned; externally peer reviewed.

Open Access This is an Open Access article distributed in accordance with the Creative Commons Attribution Non Commercial (CC BY-NC 3.0) license, which permits others to distribute, remix, adapt, build upon this work noncommercially, and license their derivative works on different terms, provided the original work is properly cited and the use is non-commercial. See: http:// creativecommons.org/licenses/by-nc/3.0/

\section{REFERENCES}

1. The Joint Commission. Sentinel Events Statistics data: root cause by event type. http://www.jointcommission.org/ sentinel_event_data_general/ (accessed 11 Apr. 2012).

2. Department of Health Expert Group (Chairman, CMO) An organization with memory, The Stationery Office Limited. 2000 http://www.dh.gov.uk/ (accessed 12 May 2012).

3. Pezzolesi C, Schifano F, Pickles J, et al. Clinical handover incident reporting in one UK general hospital. Int J Qual Health Care 2010;22:396-401.

4. Horwitz LI, Moin T, Krumholz $\mathrm{H}$, et al. Consequences of inadequate sign-out for patient care. Arch Intern Med 2008;168:1755-60. 
5. Arora V, Johnson J, Meltzer DO, et al. A theoretical framework and competency-based approach to improving handoffs. Qual Saf Health Care 2008;17:11-14.

6. Patterson ES, Roth EM, Woods DD, et al. Handoff strategies in settings with high consequences for failure: lessons for healthcare operations. Int J Qual Health Care 2004;6:125-32.

7. Farhan $\mathrm{M}$, Brown $\mathrm{R}$, Woloshynowych $\mathrm{M}$, et al. The $\mathrm{ABC}$ of handover: a qualitative study to develop a new tool for handover in the emergency department. Emerg Med J 2012; Published Online First: 3 January 2012.

8. Borowitz SM, Waggoner-Fountain LA, Bass EJ, et al. Adequacy of information transferred at resident sign-out (inhospital handover of care): a prospective survey. Qual Saf Health Care 2008;17:6-10.

9. Huckvale C, Car J, Akyama M, et al. Information technologies for patient safety. Qual Saf Health Care 2010;19:25-33.

10. Arora V, Kao J, Lovinger D, et al. Medication discrepancies in resident sign-outs and their potential to harm. J Gen Intern Med 2007;22:1751-5

11. Bhabra G, Mackeith S, Monteiro P, et al. An experimental comparison of handover methods. Ann R Coll Surg Engl 2007;89:298-300.

12. Haggerty JL, Robert RJ, Freeman GK, et al. Group continuity of care: a multidisciplinary review. BMJ 2003;327:1219-21.

13. Wong MC, Yee KC, Turner P. Clinical Handover Literature Review. eHealth Services Research Group University of Tasmania, Australia. 2008. http://www.thoracic.org.au/ (accessed 10 Nov 2011).

14. Australian Commission on Safety and Quality in Health Care. Implementation Toolkit for Clinical Handover Improvement. Sydney, 2011. http://www.safetyandquality.gov.au/ (accessed 28 Feb 2012).

15. Harvey CM, Schuster RJ, Durso FT, et al. Human factors of transition of care. In: Carayon P, ed. Handbook of human factors and ergonomics in healthcare and patient safety. Mahwah, $\mathrm{NJ}$ : Lawrence Erlbaum Associates, 2007:233-48.

16. Arora V, Johnson J, Lovinger D, et al. Communication failures in patient sign-out and suggestions for improvement: a critical incident analysis. Qual Saf Health Care 2005;14:401-7.

17. Manser T, Foster S, Gisin S, et al. Assessing the quality patient handoffs at care transitions. Qual Saf Health Care 2010;19:61-5

18. Manser T, Foster S. Effective handover communication: an overview of research and improvement efforts. Best Pract Res Clin Anaesthesiol 2011;25:181-91.

19. Brannen ML, Cameron KA, Adler M, et al. Admission handoff communications: clinician's shared understanding of patient severity of illness and problems. J Patient Saf 2009;5:237-42.

20. Boaro N, Fancott C, Baker R, et al. Using SBAR to improve communication. J Interprof Care 2010;24:111-14.

21. Starmer AJ, Spector ND, Srivastava R, et al. I-pass, a mnemonic to standardize verbal handoffs. Pediatrics 2012;129:201-4.

22. Jeffcott SA, Ibrahim JE, Cameron PA. Resilience in healthcare and clinical handover. Qual Saf Health Care 2009;18:256-60.

23. Sharit J, McCane L, Thevenin DM, et al. Examining links between sign-out reporting during shift changeovers and patient management risks. Risk Anal 2008;28:969-81.

24. Ong MS, Coiera E. A systematic review of failures in handoff communication during intrahospital transfers. Jt Comm J Qual and Patient Saf 2011;37:274-84.

25. Medlock S, Eslami S, Askari M, et al. Improved communication in post-ICU care by improving writing of ICU discharge letters: a longitudinal before-after study. BMJ Qual Saf. 2011;20:967-73.
26. Petrovic MA, Aboumatar $\mathrm{H}$, Baumgartner WA, et al. Pilot implementation of a perioperative protocol to guide operating room-to-intensive care unit patient handoffs. J Cardiothorac Vasc Anesth 2012;26:11-16.

27. Tomasello M. The Origins of Human Communication. Cambridge, MA: MIT Press, 2008:72-99.

28. Klein G, Feltovich PJ, Bradshaw JM, et al. Common ground and coordination in joint activity. In: Rouse WB, Boff KK, eds. Organizational simulation. New York: John Wiley \& Sons Inc, 2005:139-84.

29. Clark $\mathrm{HH}$. Using language. Cambridge: Cambridge University Press, 1996:191-221.

30. Vygotsky LS. Mind in Society-The Development of Higher Psychological Processes. Harvard: Harvard University Press, 1978:38-58

31. Kolbe M, Künzle B, Zala-Mezö $\mathrm{E}$, et al. Measuring coordination behaviour anaesthesia teams during induction of general anaesthetics. In: Flinn R, Mitchell L, eds. Safer Surgery Analysing Behaviour in the Operatign Theatre. Farnham Burlington, UK: Sage Publication, 2009:206-7.

32. Øvretveit JC, Shekelle PG, Dy SM, et al. How does context affect interventions to improve patient safety? An assessment of evidence from studies of five patient safety practices and proposals for research. BMJ Qual Saf 2011;20:604-10.

33. Raduma-Toma's MA, Flin R, Yule $\mathrm{S}$, et al. The importance of preparation for doctors' handovers in an acute medical assessment unit: a hierarchical task analysis. BMJ Qual Saf 2011;21:211-7.

34. Toccafondi G, Albolino S, Bellandi T, et al. Handover process: how to improve quality and safety through an ergonomic solution. Work: A Journal of Prevention, Assessment and Rehabilitation 2012;41:2941-5.

35. Gaver B, Dunne T, Pacenti E. Design: Cultural Probes. Interactions 1999;6:21-9.

36. Gurses AP, Xiao Y, Hu P. User-designed information tools to support communication and care coordination in a trauma hospital. $J$ Biomed Inform 2009;42:667-77.

37. Norman DA. The Design of Everyday Things. New York: Basic Books, 1988:187-210.

38. Fern EF. Advanced Focus Group Research. London: Sage Publication, 2001:173-89.

39. Adapted from www.uqhealthinsitu.com.au/clinicalhandover (accessed Feb 2012).

40. Denscombe M. The Good Research Guide. London: Open University Press, 2010:83-6.

41. O'Cathain A, Murphy E, Nicholl J. Why, and how, mixed methods research is undertaken in health services research in England: a mixed methods study. BMC Health Serv Res 2007;14:85.

42. Sanders EB, Stappers PJ. Co-creation and the new landscapes of design. Codesign 2008;4:5-18.

43. Gersick CJ, Hackman JR. Habitual routines in taskperforming groups. Org Beh and Human Decision Processes 1990;47:65-97.

44. Sibinga EMS, Wu AW. Clinician mindfulness and patient safety. JAMA 2010;304:2532-3.

45. Garrod S. How groups coordinate their concepts and terminology: implications for medical informatics. Methods Inf Med 1998;37:471-6. 